\title{
Algunas consideraciones sobre la Prescripción Extintiva en el Código Civil Peruano
}

\author{
Luciano Barchi Velaochaga
}

El profesor Luciano Barchi presenta

un análisis sobre la Prescripción

Extintiva en el Código Civil peruano.

Comienza explicando su naturaleza y desarrolla el porqué de su existencia como figura jurídica. Asimismo, explica las diferentes aristas relacionadas con la prescripción extintiva por medio de un análisis comparado de otros ordenamientos jurídicos como el alemán, italiano y francés.

Abogado por la Universidad de Lima. Magíster en Derecho con mención en Derecho Civil y candidato a Doctor por la Pontificia Universidad Católica del Perú. Profesor de Derecho Civil en la Facultad de Derecho de la Universidad de Lima y de la Pontificia Universidad Católica del Perú. 


\section{Prolegómeno}

La prescripción extintiva es indispensable por la necesidad de certeza de las relaciones jurídicas. De acuerdo con Molfese el instituto de la prescripción satisface una exigencia de orden público de certeza de las relaciones jurídicas, las cuales, como tienen un inicio deber tener también un final ${ }^{1}$. En tal sentido las normas sobre prescripción no pueden ser modificadas por acuerdo de las partes.

En este sentido el artículo 1990 del Código Civil establece:

"El derecho de prescribir es irrenunciable. Es nulo todo pacto destinado a impedir los efectos de la prescripción".

Más preciso es el artículo 2936 del Código Civil italiano que señala: "Es nulo cualquier pacto dirigido a modificar la disciplina legal de la prescripción". Por su lado el § 202 del Código Civil alemán (Bügerliches Gesetzbuch) modificado por la Modernisierierung des Sachuldrechts de 2004 señala:

"(1) Mediante negocio jurídico no puede atenuarse anticipadamente la prescripción para la responsabilidad por dolo.

(2) Mediante negocio jurídico no puede agravarse la prescripción con plazo

de prescripción superior en treinta años a partir del inicio legal de su cómputo".

Del texto transcrito se aprecia una tendencia a la flexibilización respecto a la prescripción extintiva.

Sólo luego que la prescripción se haya ganado; es decir, sólo luego del transcurso del tiempo establecido, se consiente la renuncia. Así, el primer párrafo del artículo 1991 del Código Civil dispone:

"Puede renunciarse expresa o tácitamente a la prescripción ya ganada".

La renuncia es un acto mediante el cual un sujeto de manera unilateral se priva de un derecho del cual es titular. La renuncia puede ser expresa o tácita. Para que se dé una renuncia tácita el comportamiento del deudor debe ser incompatible con la voluntad de beneficiarse de la prescripción. En este sentido el segundo párrafo del artículo 1991 del Código Civil señala: "Se entiende que hay renuncia tácita cuando resulta de la ejecución de un acto incompatible con la voluntad de favorecerse con la prescripción".

Molfese, Giuseppe. Prescrizione e decadenza in materia civile, Giuffrè, Milano, 2005, p. 105. Vidal Ramírez también considera que el fundamento de la prescripción es de orden público (Vidal Ramírez, Fernando. La Prescripción y la Caducidad en el Código Civil Peruano, Cultural Cusco, Lima, 1985, p. 101). 
El Código Civil francés dicta en el Título XX (Titre $X X$ ) del Libro III (Livre Troisième) denominado "Diferentes maneras de adquirir la propiedad" (Des différentes manières don ton acquiert la propriété) reglas comunes a las dos clases de prescripción: la adquisitiva y la extintiva (De la prescription et de la possession). Este esquema fue seguido por la mayoría de los Código Civiles, así por ejemplo el Código Civil peruano de 1852 .

Hoy día se reconoce que hay que separar la disciplina legislativa de la prescripción adquisitiva y de la prescripción extintiva (cosa que hace nuestro Código Civil), incluso se prefiere hablar de usucapión para referirse a la prescripción adquisitiva y hablar de prescripción solo respecto a la extintiva. Este es el caso de nuestro Código Civil².

\section{2. ¿Qué significa que la prescripción una vez iniciada continúa corriendo contra los sucesores del titular del derecho?}

De acuerdo con el artículo 1993 del Código Civil: "La prescripción comienza a correr desde el día en que puede ejercitarse la acción y continúa contra los sucesores del titular del derecho".

De acuerdo con Vidal Ramírez el artículo citado se refiere a la accesio temporis, inicialmente admitida para la usucapión:

"que consiste en la suma del tiempo que debe transcurrir para la prescripción, de modo que iniciado el decurso el decurso prescriptorio contra el titular de un derecho subjetivo sigue corriendo contra sus sucesores" ${ }^{\prime \prime}$.

El autor nacional vincula la adición del plazo posesorio prevista en el artículo 898 del Código $\mathrm{Civil}^{4}$ al segundo párrafo del artículo 1993 . Esto en nuestra opinión no es correcto.

Pensemos en el derecho de crédito. La titularidad de un crédito puede ser objeto de transferencia, como lo puede ser cualquier situación jurídica, salvo que las partes, la naturaleza de la obligación o la ley lo impidan. En otras palabras, el crédito, como la propiedad, es un bien y, por tanto, puede ser objeto de transferencia.

En tal sentido, la transferencia de la titularidad de un crédito debe ser estudiada dentro del sistema general de transferencias, tomando en cuenta sus aspectos comunes y particulares.

\footnotetext{
$2 \quad$ Aunque el Código Civil habla de prescripción adquisitiva y no de usucapión.

3 Vidal Ramírez, Fernando. La Prescripción y la Caducidad en el Código Civil Peruano, Cultural Cusco, Lima, 1985, p. 122.

4 "El poseedor puede adicionar a su plazo posesorio el de aquel que le transmitió válidamente el bien".
} 
Dentro de esta idea, debemos comprender que la transferencia de la titularidad del crédito constituye un efecto jurídico, el cual, de acuerdo con "la ley de la causalidad jurídica" responde a una causa. Es decir, que no puede producirse el efecto traslativo de la titularidad de ninguna situación jurídica subjetiva sin un hecho que constituya la realización del supuesto normativo, causa o antecedente legal necesario de tales consecuencias ${ }^{5}$.

En tal sentido, la titularidad de un crédito puede ser transferida como consecuencia de la muerte de su titular ${ }^{6}$ o por actos entre vivos ${ }^{7}$. La transferencia de la titularidad del crédito, supone la sustitución del sujeto activo original (cedente) por uno nuevo (cesionario) permaneciendo inmutada y conservándose la identidad de la relación obligatoria.

En este sentido Bianca señala: "En el curso de su existencia la relación obligatoria puede sufrir modificaciones subjetivas del lado activo y del lado pasivo. El principal evento modificativo de la obligación del lado activo es la transferencia"8. Más adelante, el profesor italiano añade:

"La vicisitud de la trasferencia puede ser identificada como sucesión en el crédito. Trasferencia y sucesión son términos equivalentes que designan el mismo fenómeno bajo dos diversos perfiles, uno relativo al objeto (el derecho se transfiere del originario al nuevo acreedor), el otro relativo a los sujeto (al acreedor originario sucede el nuevo acreedor)" ${ }^{\prime \prime}$.

Como hemos dicho la sustitución del acreedor originario (cedente) por el nuevo acreedor (cesionario) supone la subsistencia de la relación obligatoria que, aunque modificada, conserva su identidad. Sotgia, al respecto, dice:

"La permanencia inmutada del derecho (o acción), si bien produciéndose la mutación del sujeto originalmente titular, se justifica y funda con el principio de la transferibilidad del derecho a título particular (sea del lado activo que pasivo), e implica consecuentemente el pasaje del objeto del

5 Abelenda, César Augusto. Derecho Civil. Parte General. T. 2, Astrea, Buenos Aires, 1980, p. 173.

6 "Artículo 1218.-La obligación se trasmite a los herederos, salvo cuando es inherente a la persona, lo prohíbe la ley o se ha pactado en contrario"

$7 \quad$ Cesión de créditos o subrogación.

$8 \quad$ Bianca, Massimo. Diritto Civile. T.4, Giuffrè, Milano, 1993, p. 567.

9 Bianca, Massimo. Diritto Civile. T.4, Giuffrè, Milano, 1993, p. 567. 
derecho al cesionario con todas las excepciones y gravámenes por ello y de ello"10.

En el mismo sentido Bianca dice:

"La noción de trasferencia implica la identidad del derecho, en el sentido que el derecho perteneciente al nuevo acreedor es el mismo derecho ya perteneciente al acreedor originario. Ello importa, entre otras cosas, la permanencia de los derechos accesorios y, en particular, de los derechos de garantía"11.

En tal sentido, dado que la transferencia del crédito supone la subsistencia de la relación obligatoria que, aunque modificada, conserva su identidad, el sucesor asume el plazo prescriptorio que viene corriendo, como si fuera el acreedor original ${ }^{12}$. Por tanto, no se trata de sumar plazos, como ocurre con el artículo 898 del Código Civil. Estamos frente a un único y mismo plazo.

\section{La interrupción de la prescripción ${ }^{13}$}

La interrupción se da cuando el derecho, luego de un periodo de inercia de parte de su titular, viene nuevamente ejercitado. Inicia, así, a correr un nuevo periodo de prescripción sin tener en cuenta a fines del cómputo, el tiempo precedente. Como señalaba Hinestrosa:

"El decurso del término de la prescripción puede verse afectado por el advenimiento de un hecho incompatible con la causa y la función de la prescripción; delante de tal circunstancia y en mérito de ella, el tiempo corrido se borra... ${ }^{14}$, lo que implica el cómputo de un nuevo término ("borrón y cuenta nueva").

En el mismo sentido Bianca señala que "el efecto interruptivo de la prescripción se explica en razón de la incompatibilidad de las causas de interrupción con la valorización

10 Sotgia, Sergio. "Voce: Cessione di crediti e di altri diritti". En: Novissimo Digesto Italiano, Vol III, 1959, p. 138.

11 Bianca, Massimo. Diritto Civile. T.4, Giuffrè, Milano, 1993, p. 568. Esto se recoge en el artículo 1211 del Código Civil.

12 Ello explica en el caso de la cesión de créditos la responsabilidad por la veritas nominis prevista en el artículo 1212 del Código Civil, para el caso de cesión de un crédito prescrito. Permítaseme remitir Barchi Velaochaga, Luciano. "La cesión de créditos en el Código Civil peruano de 1984". En: Revista Taller de Derecho. Año I, nº. 1, enero 2002, pp. 101-134. El presente artículo también fue publicado en: Revista del Magíster en Derecho Civil. Vol 4-5. Lima: Pontificia Universidad Católica del Perú, 2000-2001, pp. 209-264.

13 El término "interrupción" deriva de la "interruptio temporis" del derecho romano.

Hinestrosa, Fernando. Prescripción Extintiva. 2ª edición, Bogotá, 2006, p. 157. 
normativa del desinterés del titular"15. A continuación de la interrupción el periodo de prescripción que ya ha corrido comienza a correr desde el momento de la interrupción, que se convierte por tanto en el término inicial de un nuevo decurso prescriptorio ${ }^{16}$.

A continuación de la interrupción el periodo de prescripción transcurrido precedentemente pierde cualquier eficacia y comienza a correr un nuevo plazo de prescripción, aunque tal efecto no se encuentra recogido expresamente en norma alguna del Código Civil (como si la hay respecto a los efectos de la suspensión en el artículo 1995 del Código Civil) ${ }^{17}$; el primer párrafo del artículo 2945 del Código Civil italiano si lo prevé expresamente: "Per effetto della interuzione s'ínizia un nuovo periodo di prescrizione".

La interrupción puede ser consecuencia de una actuación del titular del derecho como del prescribiente. Teniendo en cuenta estas circunstancias, Hinestrosa señalaba que la interrupción de la prescripción extintiva se ha clasificado usualmente en civil y natural ${ }^{18}$.

Molfese indica que las causas de interrupción de la prescripción son civiles o naturales: pueden consistir en el ejercicio de actos jurídicos o en actos materiales de goce del derecho. Los actos mediante los cuales se inicia un proceso judicial o arbitral o se reconoce un derecho ajeno son causas civiles de interrupción. El ejercicio de un derecho es causa natural, así el ejercicio de hecho de una servidumbre de paso constituye el típico ejemplo de causa natural de interrupción ${ }^{19}$.

El artículo 2257 del Anteproyecto de reforma del Código Civil francés (Título III del Libro III y del derecho de prescripción) elaborado por un grupo de civilistas bajo la dirección del profesor Pierre Catala establece que: "La prescripción puede ser interrumpida, ya naturalmente, ya civilmente". El artículo 2258 establece: "Hay interrupción natural, cuando el poseedor es privado por más de un año del goce de la cosa, sea por su antiguo propietario, sea, incluso, por un tercero". El artículo 2250: "Hay interrupción Civil cuando el deudor o el poseedor reconoce, así sea tácitamente, el derecho de aquel contra quien estaba prescribiendo". Finalmente, la Ley $\mathrm{N}^{\circ}$ 2008-

15 Bianca, Massimo. Diritto Civile. T. 7, Giuffrè, Milano, 2012, p. 601.

16 Esto se diferencia de la suspensión que paraliza el decurso de la prescripción conservando el periodo de prescripción que ya ha corrido.

El artículo 2058 del Proyecto de Código Civil elaborado por la Comisión Reformadora señalaba: 'La interrupción torna ineficaz el tiempo transcurrido y da inicio a un nuevo periodo prescriptorio". sentido el artículo 2539 del Código Civil de Colombia.

Molfese, Giuseppe. Prescrizione e decadenza in materia civile, Giuffrè, Milano, 2005, p. 105. 
561 del 17 de junio de 2008 que reformó la prescripción en materia civil no incluyó la distinción entre la interrupción natural y la civil ${ }^{20}$.

Vidal Ramírez al respecto señala:

"La doctrina suele distinguir la interrupción en civil y natural. Pero el criterio es válido en los casos en que la codificación civil da un tratamiento unitario a la prescripción, ya que la interrupción civil corresponde a la extintiva mientras que la natural a la usucapión, considerando ésta en la pérdida de la posesión (Art. 953)" y luego añade: "Nuestra codificación civil, como ya lo hemos visto, a partir del Código de 1936 ha dado un trato dual a la prescripción, lo que llevó a León Barandiarán a aseverar que la distinción carece de interés en nuestro Derecho Civil" ${ }^{\prime 21}$.

En los Principios del Derecho Europeo de los Contratos en lugar del término "interrupción" se prefiere hablar de "renovación (renewal) del plazo"22.

El artículo 1996 del Código Civil establece las causales de interrupción:

"Se interrumpe la prescripción por:

1. Reconocimiento de la obligación.

2. Intimación para constituir en mora al deudor.

3. Citación con la demanda o por otro acto con el que se notifique al deudor aun cuando se haya acudido a un juez o autoridad incompetente.

4. Oponer judicialmente la compensación".

\subsection{Intimación para constituir en mora al deudor}

Normalmente la doctrina tradicional ha utilizado como sinónimos las expresiones "constitución en mora" e "interpelación", así por ejemplo Marty señala: "La constitución en mora es la interpelación dirigida por el acreedor al deudor para exigirle el cumplimiento de sus obligaciones"23. En este mismo sentido Bianca señala: "La constitución en mora es el acto mediante el cual el acreedor requiere o intima al

$20 \quad$ Cabe señalar que el Anteproyecto regulaba conjuntamente la prescripción extintiva (prescription extinctive) y la usucapión (prescription acquisitive). Finalmente la Ley No 2008-561 del 17 de junio de 2008 que reformó la prescripción en materia civil pero sin tomar completamente el Anteproyecto, si bien mantiene dentro del Título XX tanto la prescripción extintiva como la usucapión, su regulación está separada.

Vidal Ramírez, Fernando. La Prescripción y la Caducidad en el Código Civil Peruano, Cultural Cusco, Lima, 1985, p. 140.

No obstante en la edición italiana se sigue hablando de interrupción.

23

Marty, G. Derecho Civil. Volumen II. José M. Cajica Jr (Trad.), Editorial José M. Cajica Jr., Puebla, 1952, p. 40. 
deudor a cumplir la obligación"24. En la legislación extranjera ello se aprecia en el artículo 1219 del Código Civil italiano cuando señala:

"El deudor es constituido en mora mediante intimación o requerimiento por escrito.

No es necesaria la constitución en mora:

1) Cuando la deuda deriva de hecho ilícito;

2) Cuando el deudor ha declarado por escrito de no querer ejecutar la prestación a su cargo;

3) [...".

Sin embargo, ello no es exacto por cuanto al referirnos a la constitución en mora lo hacemos para designar a las diferentes formas por las que el deudor queda incurso en la situación moratoria y, cuando hablamos de interpelación (o intimación) estamos refiriéndonos a una de aquéllas formas.

Dentro de la "mora debendr" (mora del deudor) se distinguen por la doctrina y la legislación: la mora "ex persona", cuando es necesario un acto del acreedor (interpelación o intimación) para la constitución en mora; y la mora "ex re" o "mora automática", donde no es necesaria la interpelación (o intimación); en este caso, ella se produce de pleno derecho.

La legislación comparada, en su gran mayoría, sostiene como principio general la mora "ex persona"; es decir, aquélla que se constituye mediante un acto del acreedor. Se aplica el aforismo "dies non interpellat pro homine" (el tiempo no interpela por el hombre).

El acto del acreedor es llamado interpelación, requerimiento o intimación ${ }^{25}$. El objeto de la intimación (interpelación o requerimiento) consiste en la exigencia de la ejecución de la prestación debida. El objeto de la intimación no consiste, pues, en constituir en mora al deudor, sino más bien, lograr la ejecución de la prestación. En otras palabras, el acreedor busca mediante la interpelación (o intimación) el pago. Es indiferente, si además quiere producir el efecto de la situación de mora pues ésta se producirá por imperio de la ley ("ex lege'). La situación de mora se configura como el objeto subsidiario $^{26}$; significa que la intimación nunca es generadora del efecto jurídico

Bianca, Massimo. Diritto Civile. T. 7, Giuffrè, Milano, 2012, p. 601.

Ravazzoni sostiene que "requerimiento" e "intimación" no son expresiones equivalentes pues "el requerimiento es una solicitud de la prestación pura y simple; la interpelación es la orden del acreedor al deudor para que cumpla su prestación. Ver: Ravazzoni citado por Hernández Gil, Félix. "La intimación del acreedor en la mora «ex persona»". En: Anuario de Derecho Civil, Tomo XV, Fascículo II, Madrid, 1962, p. 334, nota (5).

Padilla, René. La Mora en las Obligaciones, Astrea, Buenos Aires, 1983, p. 190. 
(situación de mora) ab initio, sino una vez que el deudor viola su contenido; es decir, cuando el deudor no ejecuta la prestación requerida por el acreedor.

En tal sentido, cuando el inciso 2) del artículo 1996 del Código Civil se refiere a "intimación para constituir en mora al deudor" no es preciso. Lo que produce el efecto interruptivo es la intimación, independientemente si ésta producirá o no la constitución en mora del deudor. Así, por ejemplo, si las partes han pactado la mora automática (mora "ex re'), el vencimiento del plazo constituirá en mora al deudor pero no producirá la interrupción de la prescripción. La interrupción de la prescripción se producirá cuando el acreedor intime al deudor, el cual ya habrá sido constituido en mora por el vencimiento del plazo.

La referencia a la "constitución en mora" nos permite afirmar que la intimación (o interpelación) que interrumpe la prescripción requiere los mismos requisitos que se necesitan para que se produzca la constitución en mora, pero independientemente si ésta se produce o no.

La interpelación (intimación) es una declaración de voluntad unilateral, potestativa del acreedor y recepticia ${ }^{27}$, lo que significa que depende de la sola voluntad del acreedor, la cual está dirigida al deudor que debe tener conocimiento de la misma; vale decir, que no es suficiente que esté dirigida a un sujeto determinado (en este caso al deudor), sino que debe llegar a conocimiento del destinatario.

Esta causal, la intimación para constituir en mora al deudor, concierne exclusivamente a la "acción personal" (derechos de crédito). No concierne a los derechos potestativos, dado que su correlato no es una situación de obligación sino una situación de sujeción.

Al respecto debe tenerse en cuenta el artículo 1333 del Código Civil según el cual:

"Incurre en mora el obligado desde que el acreedor le exija judicial o extrajudicialmente, el cumplimiento de su obligación...".

De acuerdo con el artículo citado, la intimación puede ser judicial (o arbitral) o extrajudicial $^{28}$. Teniendo en cuenta el carácter recepticio de la intimación, la interrupción de la prescripción se producirá cuando ésta llegue a conocimiento del deudor, en tal sentido, en el caso de la intimación judicial, cuando la demanda es notificada al deudor y en el caso de la intimación extrajudicial deberá tenerse en

27 Von Tuhr critica la expresión "recepticia", señalando que más apropiado es la expresión "declaraciones que exigen ser dirigidas". Ver: Von Tuhr, Andreas. Derecho Civil, Vol II.2, Depalma, Buenos Aires, 1946, p. 105. manera que aún la intimación verbal tiene eficacia interruptora, advirtiéndose que en tal evento el problema se presenta en el ámbito probatorio. Ver: HINESTROSA, Fernando. Prescripción Extintiva. 2a edición, Bogotá, 2006, p. 166. 
cuenta, por analogía, los artículos $1373^{29}$ y 1374 del Código Civil (modificado por la Ley No. 27291$)^{30}$.

Si se trata de la interrupción como consecuencia de la intimación extrajudicial la interrupción se produce en el instante en que el deudor toma conocimiento de ella y, si no ejecuta la prestación, el plazo de prescripción de la acción personal comienza a correr nuevamente ("desde cero") de manera inmediata ${ }^{31}$.

Respecto a la intimación judicial como causal de interrupción cabe preguntarse ¿Se superpone el inciso 2 con el inciso 3 del artículo 1996 del Código Civil? Responderemos esta pregunta al tratar el acápite 3.3).

\subsection{La citación con la demanda o por otro acto con el que se notifique al deudor aun cuando se haya acudido a un juez o autoridad incompetente}

Esta causal se refiere a la "citación con la demanda o por otro acto con el que se notifique al deudor". Una interpretación literal (por la referencia al "deudor") nos llevaría a sostener que esta causal sólo se refiere a la "acción personal" (derecho de crédito) y, podría tratarse, como se verá más adelante, de un supuesto ya previsto en la causal anterior (inciso 1) vale decir la intimación judicial (o arbitral).

No obstante, creemos que la interpretación debe ser más amplia y considerar que esta causa de interrupción se refiere a cualquier demanda, judicial o arbitral, con la cual el titular haga valer su propio derecho, no limitándose a un derecho de crédito. Este es el sentido del artículo 2943 del Código Civil italiano ${ }^{32}$.

Debe precisarse, que no toda demanda tiene objeto interruptivo de la prescripción, sino sólo aquellas con las cuales el demandante pretende el reconocimiento y la tutela

29 'El contrato queda perfeccionado en el momento y lugar en que la aceptación es conocida por el oferente".

'La oferta, su revocación, la aceptación y cualquier otra declaración contractual dirigida a determinada persona se considera conocida en el momento en que llegan a la dirección del destinatario, a no ser que este pruebe haberse encontrado, sin su culpa, en la imposibilidad de conocerlo.

Si se realiza a través de medios electrónicos, ópticos y otro análogo, se presumirá la recepción de la declaración contractual, cuando el remitente reciba el acuse de recibo" (el subrayado es agregado).

En este sentido Molfese, Giuseppe. Prescrizione e decadenza in materia civile, Giuffrè, Milano, 2005, p. 229. Como veremos a diferencia de la interrupción de la prescripción por citación con la demanda que el plazo de prescripción no comienza a correr de manera inmediata.

Bianca, Massimo. Diritto Civile. T. 7, Giuffrè, Milano, 2012, p. 601. 
jurídica del derecho respecto del cual se deduce la excepción de prescripción. No necesariamente supone una interpelación (pretensión de pago), así, por ejemplo, podría tratarse de una solicitud de medida cautelar anticipada ${ }^{33}$.

De acuerdo con el Codice Civile la prescripción se interrumpe con la notificación del acto con el cual se inicia un proceso, sea de conocimiento ("cognizione'), conservativo o ejecutivo. Así la prescripción se interrumpe por demandas dirigidas a promover un proceso de conocimiento, es decir un proceso dirigido a obtener una sentencia de condena, una sentencia constitutiva o una sentencia de declarativa ("accertamento") ${ }^{34}$. Eficacia interruptiva tienen también las demandas dirigidas a promover procesos conservativos, es decir, procesos cautelares o de instrucción preventiva ${ }^{35}$.

Como se desprende del inciso 3 del artículo 1996 del Código Civil la demanda debe ser notificada al punto que, conforme al inciso 1 del artículo 1997 del Código Civil la interrupción queda sin efecto si "se prueba que el deudor no fue citado con la demanda o no fue notificado con cualquiera de los otros actos a que se refiere el artículo 1996, inciso 3".

Los titulares de derechos reales sobre cosa ajena interrumpen la prescripción mediante la acción confesoria y mediante las acciones posesorias ${ }^{36}$.

No sólo debe considerarse que se interrumpe la prescripción por citación con la demanda sino también con la notificación de la reconvención ${ }^{37}$. Si bien el artículo 1997 del Código Civil no hace referencia a ella, el artículo 1997 del Código Civil, lo admite implícitamente, cuando establece que queda sin efecto la interrupción "cuando el demandado se desiste de la reconvención".

Respecto al arbitraje la Novena Disposición Complementaria del Decreto Legislativo No. 1071 establece lo siguiente:

"Comunicada la solicitud de arbitraje, se interrumpe la prescripción de cualquier derecho a reclamo sobre la controversia que se propone someter a arbitraje, siempre que llegue a constituirse el tribunal arbitral.

33 Al respecto ver el artículo 618 del Código Procesal Civil.

34 El efecto interruptivo se justifica respecto a la acción de declarativa (se pretende la declaración de la existencia o inexistencia de un derecho sin crear, modificar o extinguir una situación jurídica; así por ejemplo, que se declare la nulidad de un contrato, o que el contrato ha sido resuelto) en cuanto se trata de una iniciativa procesal que excluye la inercia del titular. Ver: Bianca, Massimo. Diritto Civile. T. 7, Giuffrè, Milano, 2012, p. 605 , nota 10.

35 Bianca, Massimo. Diritto Civile. T. 7, Giuffrè, Milano, 2012, p. 604 y siguientes.

36 Bianca, Massimo. Diritto Civile. T. 7, Giuffrè, Milano, 2012, p. 606.

37 Artículo 445 del Código Procesal Civil. 
Queda sin efecto la interrupción de la prescripción cuando se declara nulo un laudo o cuando de cualquier manera prevista en este decreto legislativo se ordene la terminación de las actuaciones arbitrales.

Es nulo todo pacto contenido en el convenio arbitral destinado a impedir los efectos de la prescripción".

\subsubsection{Efecto permanente de la interrupción: "interrupción continuada o permanente"}

El artículo 1998 del Código Civil genera algunas dudas. Veamos.

El artículo 1998 del Código Civil señala: "la prescripción comienza a correr nuevamente desde la fecha en que la resolución que pone fin al proceso queda ejecutoriada". Cabe entonces preguntarse ¿Qué pasa mientras dura el proceso?

A diferencia de lo que ocurre con la intimación extrajudicial que la interrupción opera instantáneamente en cuanto aquella llega a conocimiento del deudor, en el caso de la citación con la demanda, la interrupción se prolonga desde ese momento hasta la fecha en que la resolución que pone fin al proceso queda ejecutoriada; se trata de un supuesto de "interrupción continuada o permanente" ${ }^{\text {"38. }}$

En tal sentido, no se trata de un supuesto de "suspensión de la prescripción", como dice Hinestrosa ${ }^{39}$, porque cuando la resolución que pone fin al proceso queda ejecutoriada, el plazo de prescripción comienza a correr nuevamente (desde cero), no es que la prescripción reanude su curso adicionándose el tiempo transcurrido anteriormente a la notificación de la demanda. No obstante, resulta interesante tener en cuenta que el Anteproyecto de Reforma del Código Civil francés (Título III del Libro III y del derecho de prescripción) si considera que se suspende la prescripción durante el proceso, así el artículo 2267 del establece: "La prescripción se suspende durante el proceso hasta su finalización".

Por otro lado, respecto al artículo 1998 del Código Civil cabe preguntarse ¿siempre que la resolución que pone fin al proceso queda ejecutoriada "la prescripción comienza a correr nuevamente"?

Bianca, Massimo. Diritto Civile. T. 7, Giuffrè, Milano, 2012, p. 602.

Hinestrosa señalaba: "Con todo, la posición dominante sigue siendo la de tomar la demanda $y$, en su caso, el requerimiento como actos de ejercicio del derecho que implican interrupción. Otra cosa es que mientras el proceso concluye, no corra el término de prescripción, es decir que su curso se suspende". Ver: Hinestrosa, Fernando. Prescripción Extintiva. 2ª edición, Bogotá, 2006, p. 153. 
Para poder responder esta pregunta debe distinguirse como lo hace el Código Procesal Civil, que el proceso judicial puede concluir: (i) sin declaración sobre el fondo (artículo 321); o, (ii) con declaración sobre el fondo (artículo 322).

En el caso que el proceso judicial concluya sin declaración sobre el fondo, porque el demandante (acreedor) se desiste de la demanda ${ }^{40}$ o se declara el abandono del proceso ${ }^{41}$, queda sin efecto la interrupción; es decir, se debe considerar que nunca hubo interrupción, de acuerdo al artículo 1997 del Código Civil ${ }^{42}$.

En el caso que el proceso judicial concluya con declaración sobre el fondo y, por ejemplo, se declare fundada la demanda, en realidad, no comienza a correr nuevamente el plazo de prescripción de la acción personal, en realidad, comienza a correr un nuevo plazo de prescripción (diez años) que el que corresponde a la acción "que nace de una ejecutoria", conforme lo previsto en el inciso 1 del artículo 2001 del Código Civil. Lo mismo ocurrirá cuando el proceso concluye porque el demandado se allana al petitorio.

A fines de la interrupción de la prescripción en los procesos arbitrales la prescripción se interrumpe con la solicitud de arbitraje sujeta a la constitución del tribunal arbitral. En tal sentido, si se presenta una solicitud de arbitraje pero no llega a constituirse el tribunal arbitral debe entenderse que no se ha producido el efecto interruptivo. Si se llega a constituir el tribunal arbitral, de acuerdo con la Novena Disposición Complementaria del Decreto Legislativo No. 1071, la interrupción queda suspendida hasta que el laudo ya no sea impugnable o la impugnación haya sido decidida mediante sentencia con calidad de cosa juzgada. Queda sin efecto la interrupción de la prescripción cuando se declara nulo un laudo o cuando de cualquier manera prevista en este decreto legislativo se ordene la terminación de las actuaciones arbitrales.

40 De acuerdo con el artículo 340 del Código Procesal Civil el desistimiento puede ser: (i) Del proceso o de algún acto procesal; (ii) De la pretensión. De conformidad con el artículo 343 del Código Procesal Civil "el desistimiento del proceso lo da por concluido sin afectar la pretensión" Según el artículo 344 del Código Procesal Civil "la resolución que aprueba el desistimiento de la pretensión, produce los efectos de una demanda infundada con la autoridad de cosa juzgada".

41 Según el artículo 346 del Código Procesal Civil cuando el proceso permanezca en primera instancia durante cuatro meses sin que se realice acto que lo impulse, el Juez declarará su abandono de oficio o a solicitud de parte o de tercero legitimado. De acuerdo al artículo 351 del Código Procesal Civil el abandono pone fin al proceso sin afectar la pretensión y restituye las cosas al estado que tenían antes de la demanda. $\mathrm{Si}$ por segunda vez, entre las mismas partes y en ejercicio de la misma pretensión, se declara el abandono, se extingue el derecho pretendido y se ordena la cancelación de los títulos del demandante, si ello hubiera lugar.

Nos remitimos al acápite 3.3. 


\subsubsection{Demanda interpuesta ante juez 0 autoridad incompetente}

De acuerdo con el inciso 3 del artículo 1996 se interrumpe la prescripción por citación con la demanda "aun cuando se haya acudido a un juez o autoridad incompetente". Ello comprende el arbitraje, en cuanto se determine que el árbitro o el tribunal arbitral no eran competentes.

Esto se justifica por cuanto lo que importa es que el deudor conozca que el acreedor hace valer su derecho.

\subsection{3. Ámbito de extensión del efecto interruptivo de la demanda}

De acuerdo con Bianca: "la interrupción de la prescripción concierne al derecho hecho valer en el proceso" ${ }^{\prime 4}$. De acuerdo con el autor italiano el efecto interruptivo no debe extenderse a los derechos accesorios que no hayan sido comprendidos en la demanda, no obstante, la jurisprudencia italiana ha admitido que la demanda que tiene como objeto el pago de la suma de capital interrumpe el curso de la prescripción relativa a los intereses ${ }^{44}$.

En el mismo sentido Hinestrosa señalaba:

"De más está advertir que la demanda con relevancia interruptora de la prescripción no es ni puede ser otra que aquella relativa al ejercicio del derecho en cuestión, o como lo pone de presente la jurisprudencia, «la demanda susceptible de obrar la interrupción civil de la prescripción es la que versa sobre la acción que se trata de prescribir y no de una demanda cualquiera" ${ }^{\prime 4}$.

\section{3. ¿Se superpone el inciso 2 con el inciso 3 del artículo 1996 del Código Civil?}

Como hemos señalado el inciso 2 del artículo 1996 del Código Civil comprendería, en principio, tanto la interpelación (intimación) extrajudicial como la judicial (o arbitral), de esta manera, según el inciso 2 de la norma citada, la intimación judicial (o arbitral) produciría la interrupción de la prescripción.

Ahora bien, la intimación judicial (o arbitral) supone la interposición de una demanda en virtud de la cual el acreedor pretende la ejecución de la prestación por el deudor en tal sentido cabe preguntarse ¿Qué ocurre si la intimación judicial se realiza ante juez incompetente? Para efectos de la interrupción de la prescripción ¿Resulta de aplicación

\footnotetext{
43 Bianca, Massimo. Diritto Civile. T. 7, Giuffrè, Milano, 2012, p. 615.

44 Bianca, Massimo. Diritto Civile. T. 7, Giuffrè, Milano, 2012, p. 616.

$45 \quad$ Hinestrosa, Fernando. Prescripción Extintiva. 2a edición, Bogotá, 2006, p. 165.
} 
el inciso 2 o el inciso 3 del artículo 1996 del Código Civil? De acuerdo con el artículo 1998 del Código Civil ¿No se produce la "interrupción continuada o permanente"?

Veamos el siguiente caso: Primus es acreedor de Secundus. Mediante escrito de fecha 29 de septiembre de 2012, Primus interpone demanda ante el Sexto Juzgado del Callao contra Secundus exigiéndole el pago del monto adeudado. Con fecha 30 de octubre de 2012, Secundus formula excepción de convenio arbitral. Por Resolución No. 5 de fecha 24 de mayo de 2013 se declaró fundada la excepción de convenio arbitral formulada por Secundus. Con fecha 26 de mayo de 2013, Primus interpuso recurso de apelación contra la Resolución No. 5 que declaró fundada la excepción de convenio arbitral. Mediante Resolución No. 14 de fecha 27 de octubre de 2013se confirmó la Resolución No. 5. Con fecha 4 de enero de 2014 se interpuso recurso de casación contra la Resolución No. 14. A través de Auto Calificatorio del Recurso de Casación No. 3352005 de fecha 17 de junio de 2014 se declaró improcedente el recurso de casación. Mediante Resolución No. 17 de fecha 25 de agosto de 2014 se pone fin al proceso judicial, disponiéndose el archivo del mismo.

La demanda interpuesta por Primus supone una intimación judicial (requerimiento de pago) que con su notificación constituye en mora a Secundus conforme al artículo 1333 del Código Civil, entonces cabe preguntarse ¿estamos en el supuesto del inciso 2 o del inciso 3 ?

Para la intimación judicial se ha acudido a juez incompetente; no obstante, la doctrina acepta que la constitución en mora se producirá incluso en el caso que la interpelación judicial (demanda) se interpusiera ente un juez incompetente, siempre que llegue a conocimiento del deudor, teniendo el valor de un requerimiento extrajudicial. Igualmente si una demanda en la cual se reclama la ejecución de la prestación (interpelación judicial) es procesalmente improcedente, puede ser utilizada como requerimiento extrajudicial desde que sea conocida por el deudor, pues, como señala Hernández Gil: "[...] aún en este caso se le hace saber por el acreedor la voluntad de pago $^{\prime \prime 4}$.

Por lo expuesto, entonces, la intimación judicial efectuada ante juez incompetente permite constituir en mora al deudor $y$, por tanto, interrumpe la prescripción desde que la demanda es notificada al deudor. Pero, si se considera que resulta de aplicación el inciso 2 y no el inciso 3 del artículo 1996 del Código Civil ocurriría que, conforme al artículo $1998^{47}$, no se daría la "interrupción continuada o permanente".

46 Hernández Gil, Félix. "La intimación del acreedor en la mora «ex persona»". En: Anuario de Derecho Civil, Tomo XV, Fascículo II, Madrid, 1962, p. 349-350.

47 "Si la interrupción se produce por las causas previstas en el artículo 1996, incisos 3 y 4, la prescripción comienza a correr nuevamente desde la fecha en que la resolución que pone fin al proceso queda ejecutoriada". 
De acuerdo con lo dicho, en mi opinión, para evitar estas discusiones, debe entenderse que el inciso 2 del artículo 1996 del Código Civil sólo se refiere a la intimación extrajudicial y el inciso 3 comprende (aunque no exclusivamente) la intimación extrajudicial.

Asimismo, creemos que los supuestos previstos en el inciso 2 y 3 del artículo 1997 del Código Civil requieren ser revisado. Veamos. Si tratándose de una intimación judicial el proceso judicial al que da lugar concluye sin declaración sobre el fondo, porque el demandante (acreedor) se desiste del proceso $^{48}$ deja sin aplicación el efecto continuado o permanente de la interrupción, pero no debería quedar sin efecto la interrupción como lo señala el artículo 1997 del Código Civil. En tal caso, debería ser considerado como un supuesto de intimación extrajudicial y, por tanto, considerar que la interrupción se produjo con la notificación de la demanda (de la intimación) y que desde ese momento el plazo de la prescripción comenzó a correr nuevamente. Lo mismo, debería ocurrir con el abandono del proceso.

En este sentido se pronuncia Molfese al comentar el segundo párrafo del artículo 2945 del Código Civil italiano ${ }^{49}$. El autor italiano señala que, en el caso que se produzca el abandono del proceso, no se aplica el efecto permanente de la interrupción a que se refiere el artículo 2945 [1998 del Código Civil], pero si el proceso concluye por abandono del proceso el efecto interruptivo se mantiene y el nuevo periodo de prescripción comienza a correr desde la fecha del acto interruptivo (notificación de la demanda) $)^{50}$.

\section{4. ¿La prescripción puede ser interrumpida durante el periodo de suspensión?}

Bianca nos señala que en la doctrina y jurisprudencia italiana se discute si la prescripción puede ser interrumpida durante el periodo de suspensión. La jurisprudencia se ha manifestado en sentido negativo, no obstante, para el autor italiano esta tesis no encuentra justificación normativa puesto que la eficacia del acto

Si se trata del desistimiento de la pretensión en realidad el asunto es indiferente.

"[...] Si la interrupción se ha producido mediante alguno de los actos indicados en los primeros dos párrafos del artículo 2943 [interrupción por notificación del acto con el cual se inicia un proceso], la prescripción no corre hasta el momento en el cual la sentencia adquiere la calidad de cosa juzgada [...]". Texto similar al artículo 1998 del Código Civil).

Molfese, Giuseppe. Prescrizione e decadenza in materia civile, Giuffrè, Milano, 2005, pp. 229-230. En este sentido se señala: "La interposición de la demanda judicial interrumpe la prescripción, pero si seguidamente el proceso iniciado con la demanda se extingue, la prescripción comienza a correr desde la fecha de la notificación del acto introductivo del proceso. Ver: Trib. Rimini, 10.3.1989, Manetti c. Calcinari Ausidei; AGCSS, 1991, 766. Ver: Molfese, Giuseppe. Prescrizione e decadenza in materia civile, Giuffrè, Milano, 2005, p. 235. 
interruptivo no es, en tal situación, prohibida por alguna norma. La doctrina, en cambio, está orientada a admitir la eficacia de los actos interruptivos pero no existe unanimidad respecto del momento de tal eficacia. Según la opinión que prevalece, la eficacia interruptiva se produciría al momento de la cesión de la causa de suspensión de la prescripción. Para Bianca, esta opinión tampoco encuentra confirmación normativa en cuanto la ley no prevé una interrupción con efecto diferido ${ }^{51}$.

Para el autor italiano, mayor crédito merece la opinión según la cual el acto interruptivo realizado durante el periodo de suspensión interrumpe inmediatamente la prescripción. La eficacia de los actos interruptivos es normalmente inmediata ${ }^{52}$.

\section{La suspensión de la prescripción: suspensión de la prescripción entre los cónyuges durante la vigencia de la sociedad de gananciales}

El artículo 1994 del Código Civil establece las causales de suspensión de la prescripción. Como bien lo señala BiANCA:

"La suspensión, a diferencia de la interrupción, no borra el periodo de prescripción ya transcurrido. Cuando cesa la suspensión la prescripción retorna a correr y, a efectos del cómputo de la prescripción, el periodo corrido anteriormente se suma al periodo de prescripción corrido sucesivamente ${ }^{\prime \prime 53}$.

Lo señalado se recoge en el artículo 1995 del Código Civil que dispone:

"Desaparecida la causa de suspensión, la prescripción reanuda su curso adicionándose el tiempo transcurrido anteriormente".

El Código Civil prevé dos grupos de causas de suspensión: (i) un primer grupo de causas se refiere a las relaciones que se dan entre las partes (ejemplo: entre los cónyuges, entre los menores y sus padres o tutores, entre los incapaces y sus curadores, etc.) y tiene como principal justificación la "dificultad moral que en tales relaciones puede implicar el ejercicio del derecho" ${ }^{\prime 54}$. Debe quedar claro, entonces, que la suspensión de la prescripción no supone la imposibilidad de que el titular ejercite su derecho sino la comprensión legal que no lo haga en tal situación. Así, por ejemplo, en el caso de los cónyuges, la causal de suspensión no impide que el titular del crédito requiera el pago de la deuda. Pero si no lo hace, no lo castiga con la prescripción.

Un segundo grupo está referido a la condición del titular del derecho (mientras sea imposible reclamar el derecho ante un tribunal peruano).

$\begin{array}{ll}51 & \text { Bianca, Massimo. Diritto Civile. T. 7, Giuffrè, Milano, 2012, p. } 603 . \\ 52 & \text { Bianca, Massimo. Diritto Civile. T. 7, Giuffrè, Milano, 2012, p. } 604 . \\ 53 & \text { Bianca, Massimo. Diritto Civile. T. 7, Giuffrè, Milano, 2012, p. } 579 . \\ 54 & \text { Bianca, Massimo. Diritto Civile. T. 7, Giuffrè, Milano, 2012, p. } 579 .\end{array}$ 
Debe tenerse en cuenta que las reglas referidas a la suspensión de la prescripción están orientadas a favor del titular del derecho, normalmente a favor del acreedor.

La jurisprudencia y la mayor parte de la doctrina italiana atribuyen a las causas de suspensión carácter taxativo, excluyendo que las disposiciones sobre suspensión sean aplicables por analogía ${ }^{55}$. Esta tesis se basa fundamentalmente en el artículo 2943 del Código Civil italiano que establece: "É nullo ogni patto diretto a modificare la disciplina legale della prescrizione".

A diferencia de lo que sostiene respecto a las causales de interrupción, VIDAL RAMÍREZ señala que: "La suspensión, pues, sólo puede producirse por las causales que taxativamente enumera el Art. $1994^{\prime \prime 56}$. Sin embargo, como ya lo expresamos el hecho que sea una enumeración taxativa no significa que mediante ley puedan preverse otras causales, así por ejemplo, el caso del artículo 19 de la Ley de Conciliación, Ley No. 26872 (modificado por el artículo 1 del Decreto Legislativo No. 1070) que establece:

"Los plazos de prescripción establecidos en la normatividad vigente se suspenden a partir de la fecha de presentación de la solicitud de Conciliación Extrajudicial hasta la conclusión del proceso conciliatorio conforme al artículo 15".

Hinestrosa comentaba que "la relación conyugal entre acreedor y deudor ha sido considerada siempre, universalmente, como causal de suspensión de la prescripción ${ }^{\prime \prime 57}$. Hoy día, como veremos, se amplía a los convivientes (inciso 3 del artículo 1994 del Código Civil).

El inciso 2 del artículo 1994 del Código Civil establece que se suspende la prescripción entre los cónyuges "durante la vigencia de la sociedad de gananciales". La pregunta que cabe es, si esta causa de suspensión tiene como justificación la dificultad moral que en tal situación puede implicar el ejercicio del derecho ¿por qué limitarlo a los cónyuges durante la vigencia de la sociedad de gananciales? ¿Acaso esa misma razón no se justifica en el caso de los cónyuges que opten por el régimen de separación de patrimonios?

El inciso 2 del artículo 2054 del Proyecto de Código Civil elaborado por la Comisión Reformadora no establecía una distinción sobre la base del régimen patrimonial

55 Bianca reconoce que un sector doctrinario italiano tiene una opinión contraria inclinándose por la aplicación analógica. La tesis que excluye la analogía puede dar a un problema de constitucionalidad de la norma en la medida que esta no comprenda casos en los cuales la suspensión de la prescripción resulta justificada. Ver: BIANCA, Massimo. Diritto Civile. T. 7, Giuffrè, Milano, 2012, p. 580.

Vidal Ramírez, Fernando. La Prescripción y la Caducidad en el Código Civil Peruano, Cultural Cusco, Lima, 1985, p. 128.

Hinestrosa, Fernando. Prescripción Extintiva. 2a edición, Bogotá, 2006, p. 147. 
adoptado por la sociedad conyugal, así se suspendía la prescripción: "entre el marido y su mujer, durante el matrimonio".

El inciso 2 del artículo 1157 del Código Civil de 1936 tampoco lo hacía, así se suspendía la prescripción: "entre el marido y su mujer, durante el matrimonio".

Vidal Ramírez, a pesar que en su proyecto no establecía la limitación, la justifica diciendo:

"Lo que el Código quiere, entonces, es que habiendo una relación jurídica patrimonial, el decurso prescriptorio se suspenda si las personas que son la parte acreedora y deudora, respectivamente, se conviertan en cónyuges adoptando el régimen de la sociedad de gananciales, o que habiendo adoptado el régimen de separación de patrimonios lo sustituyen por el de sociedad de gananciales ${ }^{\prime \prime 58}$.

En nuestra opinión esta distinción establece un trato diferenciado que no tiene ninguna justificación. En efecto, poco importa si el régimen patrimonial que adopten los cónyuges. La razón de suspender la prescripción en dicho caso es que el legislador considera justificado que durante el matrimonio el cónyuge acreedor no ejerza su derecho de crédito. Ello, debe advertirse, no supone que el crédito se torne inexigible, en realidad, el cónyuge acreedor podría exigir la ejecución de la prestación debida por el cónyuge deudor. Así, si Primus y Mesalina son acreedor y deudor respectivamente y luego se casan, en estricto, independientemente del régimen patrimonial adoptado, debería producirse la suspensión.

Por ello me parece más razonable la solución que brindan los Código Civiles más representativos. Así, por ejemplo, el inciso 1 del artículo 2941 del Código Civil italiano que señala, de manera general, que se suspende la prescripción "tra i coniugr".

El § 204 del BGB establecía ya la suspensión de la prescripción entre los cónyuges durante todo el tiempo en el que dure el matrimonio, a raíz de su modificación el actual $\S 207$ establece, de manera mucho más precisa lo siguiente:

"(1) La prescripción de pretensiones entre cónyuges queda suspendida mientras dura el matrimonio. Lo mismo rige para pretensiones entre:

1. Convivientes en pareja de hecho mientras se mantiene la pareja de hecho.

58 Vidal Ramírez, Fernando. La Prescripción y la Caducidad en el Código Civil Peruano, Cultural Cusco, Lima, 1985, p. 129. Rubio Correa parece aceptar que la suspensión de la prescripción entre cónyuges sea sólo la vigencia de la sociedad de gananciales (Rubio Correa, Marcial. "Prescripción y Caducidad. La extinción de acciones y derechos en el Código Civil". En: Biblioteca Para Leer el Código Civil. Volumen VII, Pontificia Universidad Católica del Perú, Lima, 1989, p. 49). 


\section{2. $[\ldots]^{\prime \prime}$}

El Anteproyecto de Reforma del Código Civil francés en el artículo 2269 establece concretamente que prescripción "no corre entre esposos". El artículo 2236 del Código Civil francés modificado por la Ley No. 2008-561 del 2008 finalmente establece:

"Elle ne court pas ou est suspendue entre époux, ainsi qu'entre partenaires liés par un pacte civil de solidarité".

En tal sentido, en nuestra opinión, sería recomendable la modificación del inciso 2 del artículo 1994 del Código Civil de tal manera de suspender la prescripción entre los cónyuges independientemente del régimen patrimonial que adopten. 